\title{
Evolution of Municipal Waste in the EU - Portugal, Croatia, and Netherlands
}

\author{
P. Matos, S. Paixão, J. P. Figueiredo, and A. Ferreira
}

\begin{abstract}
The waste represent a huge loss of resources either in the form of materials or energy". The more waste is produced, the more wastage of resources result, therefore producing less "trash" should be a high-priority for any policy that manages waste.

Thereupon, the objective of this study was to evaluate the evolution of Municipal Waste in Portugal, Croatia and Netherlands, in order to comprehend the amount of waste produced and its processing. It is a systematic review of the documents of the international entities, which are the European Environment Agency e European Commission.

In a nutshell, the values showed that there were a positive development in the area of the municipal waste and there was a trend to decline its production, such as the deposition of municipal waste in landfills, unlike the recycling that has being increased.
\end{abstract}

Index Terms-Environment, European Union, municipal waste, production.

\section{INTRODUCTION}

Over the years, the amount of waste that mankind produces has been increasing, due to the demographic development and faster economics in some regions of the world [1]

"The waste represents a huge loss of resources either in the form of materials or energy" [2]. The more wastes are produced, the larger is the waste of resources - and this is the epicenter around which orbits a huge constellation of problems. Producing less "trash" should be a priority for any policy that generate waste [3]. In Europe are produced annually about 200 million tons of Municipal Waste (MW), representing a kilogram per person and per day [2]. The base of the waste policy in the European Union (EU) is a Resolution of the Council of Ministers of the Environment and the Directive 2008/98/EC which are based on some fundamental principles, among them the hierarchy that should be applicable to waste management: 1 . Prevention and reduction; 2 . Preparing for reuse; 3 . Recycling; 4 . Other types of Recycling and energy recovery; 5. Elimination. This policy also states that the EU should be self-sufficient in the treatment of their waste and that the Member States should drive their waste policies in this direction [4].

Manuscript received July 27, 2015; revised November 12, 2015. This work was supported in part by the Department of Environmental Health Coimbra Health School, Polytechnic Institute of Coimbra, 3046-854, Portugal. Carbonic Footprint versus Time in Porto-Lisbon Route.

P. Matos, S. Paixão, and A. Ferreira are with the Department of Environmental Health, Coimbra Health School, Polytechnic Institute of Coimbra, 3046-854, Portugal (e-mail: patriciamatos.93@gmail.com, supaixao@estescoimbra.pt, anaferreira@estescoimbra.pt).

J. P. Figueiredo is with the Department of Complementary Sciences Coimbra Health School, Polytechnic Institute of Coimbra, 3046-854, Portugal (e-mail: jpfigueiredo@estescoimbra.pt).
In Portugal - a country with a population of approximately 11 million and member of the EU for 29 years - the growing volume of MW has become a concern for the municipalities, either due to lack of space, either due to the solutions and costs to resolve this problem [5].

According to data published by Eurostat, the statistical department of the EU, the production of MW in Portugal increased by $25 \%$ between 1995 and 2013 [6]. Thus, it is important to develop and update frequently the legal framing of this sector, as well as the creation of a Strategic Plan of Municipal Solid Waste (SPMSW).

The SPMSW defines the strategy for the management of $\mathrm{MW}$, at a national level, sets out the priorities in the field of management of MW, the target to be achieved, the actions to be implemented and the guiding rules of the action plans in this area. The first version was published in 1997, the SPMSW, which led to the closure of more than 300 "dumps" existing in Portugal, the launch of selective collection and the promotion of recycling through the installation of eco points and garbage processing centers, the composting valuing and the construction of a infrastructure for recovery (central energy recovery) and disposal (controlled landfills) [7]. At this moment, it is in fact the SPMSW 2020, both in Portugal and in other EU countries, that maintains the goal of ensuring a high level of environmental protection and public health.

Croatia - country with about 4 million people - became member of the EU recently, in the July 1st, 2013, and so it was necessary to make some changes in it is the legal framework in order to be in accordance with the Waste Directive framework. Due to this recent entry in the EU, Eurostat only has statistical data on the production of MW from the year 2004 [8].

Such as Portugal, Croatia implemented a management plan of MW for the period 2007-2015, serving as a framework document for the waste management strategies and for the development of individual projects that fits in the waste management systems of each county. The concept of the plan is based on the waste management hierarchy which gives priority to waste prevention, recycling, reuse and other types of recovery [8].

The Netherlands - country with about 17 million people together with Belgium and Luxembourg formed the Benelux (BE-Belgium, the Netherlands NE-, LUX-Luxembourg) and was originated the EU in the year 1960. Unlike to most EU countries, in the Netherlands the waste production rate decreased by $2 \%$ from 1995 to 2013 [9].

Thereupon, this country has been at the forefront of EU policies on waste management, influencing European strategies that have been reformulated in recent years. According to one of the objectives proposed by Waste Framework Directive by 2020 in the EU, the Netherlands is a 
pioneer in the recycling of waste, thus fulfilling the objective of $50 \%$ in 2010. On the contrary, Croatia and Portugal reached $4 \%$ and $19 \%$, respectively [10].

Like the other EU countries, the Netherlands has a Strategic Plan for Management's MW for the period 2009-2015. The overall goals of the second MW Management Plan are as follows: 1. To limit the growth in waste production (decoupling of economic growth); 2. To reduce the environmental impact of waste (optimize recovery and reuse); 3. To minimize the environmental impacts of production chains (extraction of raw materials, production and reuse) [10].

Taking into account the current situation in each country, it is imperative that each citizen has a fundamental role in MW management, contributing to efficient use of different collection systems and, in turn, reducing its production through conscious attitudes, as well as practicing frequent behaviors that promote the reduction, reuse and waste recovery [11].

The objective of this study was to evaluate the evolution of MW in the three above-mentioned countries (Portugal, Croatia and the Netherlands) in order to understand the amount of MW produced and the treatment used. These points were needed to see if there have been significant improvements over the years and if Portugal, Croatia and the Netherlands are the best way to fulfill the goals of the Waste Framework Directive 2008/98 / EC of the EU for the year 2020.

\section{MATERIAL AND METHODS}

This study is a systematic review of international organizations documents, European Environment Agency (EEA) and European Commission (EC), which studied the evolution of the MW in the EU over the years.

It is a descriptive study of macro indicators related to the countries Portugal, Croatia and Netherlands, where it was evaluated the production of MW, the advancement of recycling and disposal in landfills by the year 2013.

The identification of the documents has been made through bibliographic research on the basis of Eurostat and the search strategy used was: "Management Waste in Portugal EU", "Management Waste in Croatia EU" and "Management Waste in the Netherlands EU".

The inclusion criteria were the MW, due to problems related to the environment and public health, and the countries belonging to the European Community, namely one of the founding countries of the EU the Netherlands, Portugal which enjoys the title of state member for about 29 years and Croatia that is the most recent member of the EU.

In relation to the criteria of exclusion, were excluded all countries that are not members of the European Community and all other type of waste, such as industrial waste, medical waste and other waste.

\section{Results}

Fig. 1 refers to the evolution of the MW per capita in Portugal between 2001 and 2010. As can be seen, there is a slow increase from 2002 to 2010. According to more specific data from Eurostat, the increase was $443 \mathrm{Kg}$ of $\mathrm{MW}$ per capita in 2002 to $514 \mathrm{Kg}$ of MW per capita in 2010 .

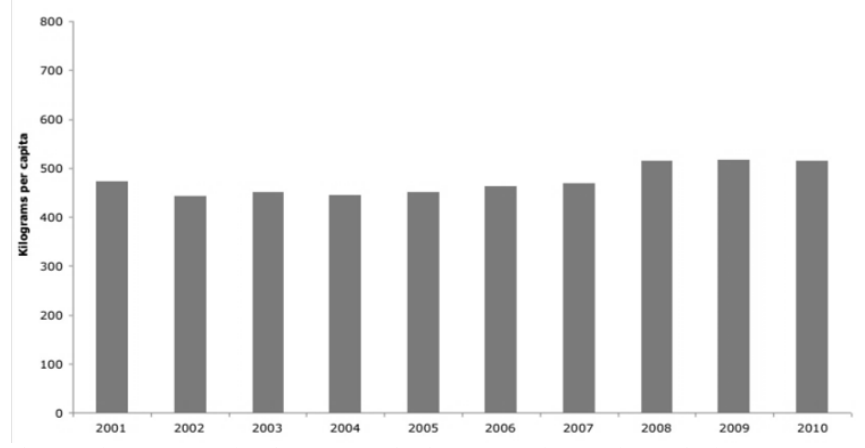

Fig. 1. The MW production per capita in Portugal over the period 2001-2010.

Fig. 2 shows the results of the development of MW per capita in Croatia, between 2004 and 2010. It should be noted that there is an increase over the years, $295 \mathrm{Kg}$ of MW per capita in 2004 to $369 \mathrm{Kg}$ of MW per capita in 2010. The year in which there was a greater production of MW was in 2008 , with $403 \mathrm{Kg}$ per capita.

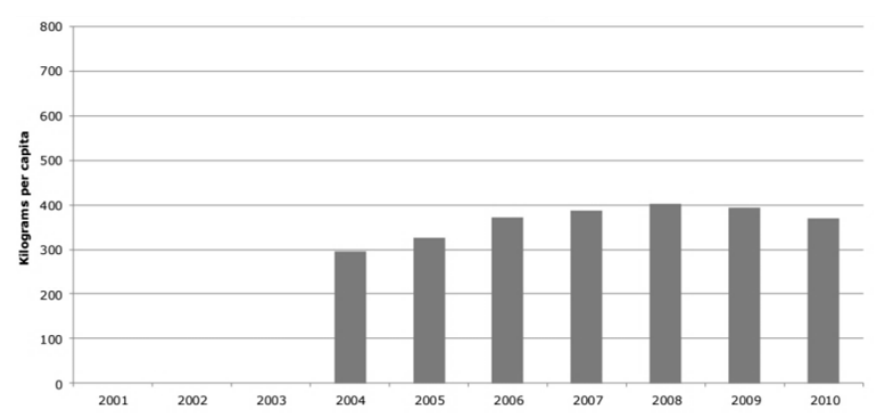

Fig. 2. The MW production per capita in Croatia over the period 2004-2010.

Fig. 3 presents the development of production of MW per capita in the Netherlands, from 2001 to 2010. The production of MW remained very stable over the years, reaching in 2007 the highest value, about $620 \mathrm{Kg}$ of MW per capita. The lowest value is recorded in 2003 and according to the European Environment Agency, this value was due to a hot and dry summer, resulting in a smaller amount of MW. For the first time in 2010, the production of MW fell below $600 \mathrm{Kg}$ to $595 \mathrm{~kg}$ per capita.

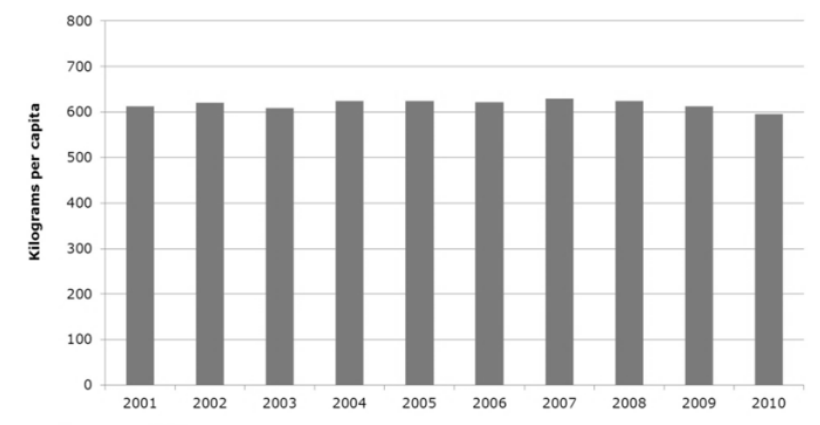

Fig. 3. The MW production per capita in Netherlands in the period 2001-2010.

Fig. 4 shows the statistical data on the evolution of recycling MW in Portugal, between the years 2001-2010, and the projection of the future of recycling by the year 2020. In 2002 there is a sharp decline, but despite the recycling rate is still very far from what is expected, there is a gradual rise from the year 2002. The stabilization observed in 2009-2010 can be an effect of the economic crisis, so it can also be seen 
in Fig. 2 that the production of waste stopped increasing at this period. Thereupon Portugal needs to make an exceptional effort to fulfill the goal of recycling $50 \%$, imposed by Directive 2008/98 / EC.
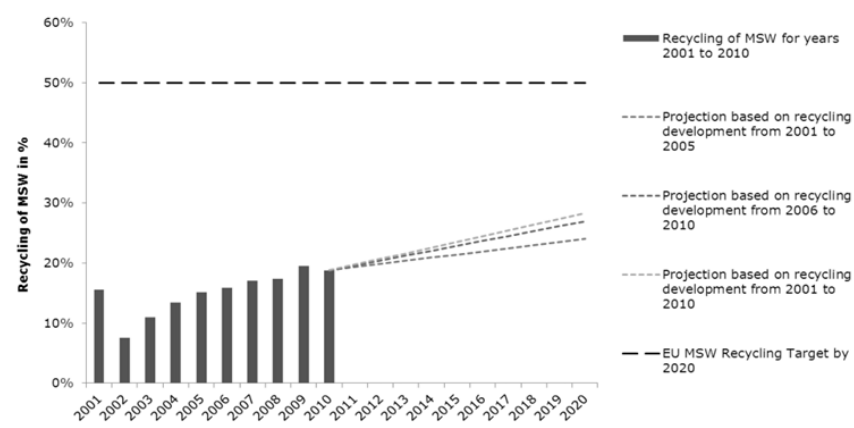

Fig. 4. Development and future of recycling in Portugal in the 2001-2020 period.

Fig. 5 shows the development of the recycling of MW in Croatia in the period 2007-2010 and the projection made of recycling by the year 2020. As can see, the recycling rate in this country is still very low in comparison with other countries, since this rate was only described from the year 2007. In 2010 Croatia only managed to reach the $4 \%$ of recycling, so it is mandatory that this country to take imminent measures for achieving the 50\% recycling in 2020.

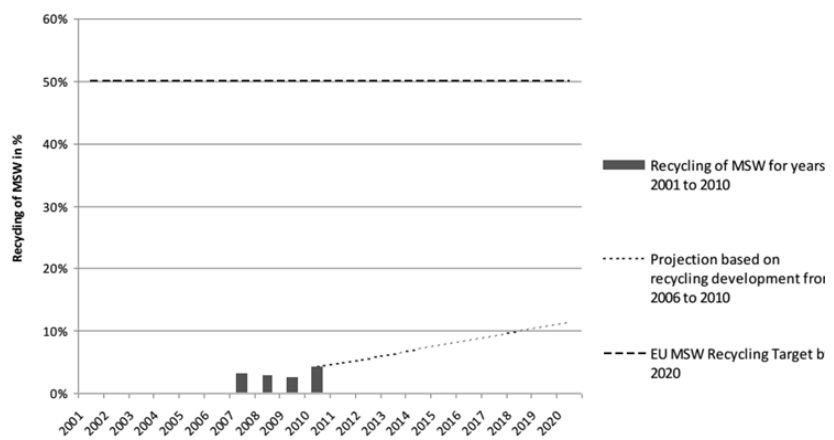

Fig. 5. Evolution and future of recycling in Croatia in the 2007-2020 period.

Fig. 6 refers to the evolution of recycling of MW in the Netherlands, between 2001-2010 and the projection of the future of recycling by the year 2020. Since 2001 the Netherlands has a high rate of recycling, compared with other countries. Thus, from 2001 to 2010 there was an increase of $6 \%$, from $45 \%$ to $51 \%$ of recycling. Therefore, was observed that the Netherlands has already fulfilled the goal of $50 \%$ recycling, and you can reach $55 \%$ to $60 \%$ by the year 2020 .

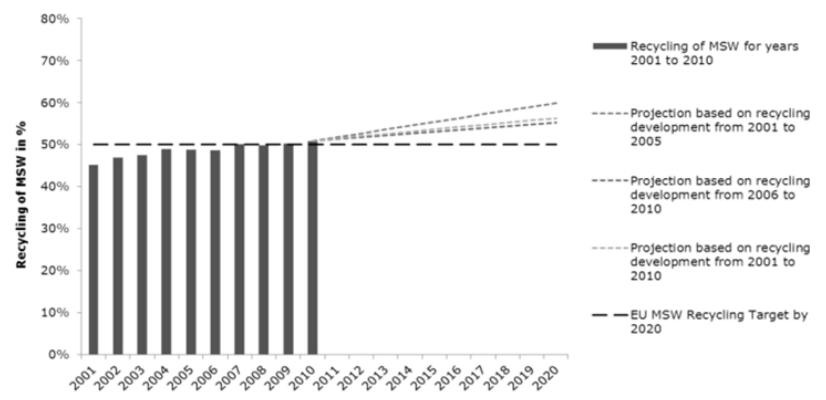

Fig. 6. Development and future of recycling in the Netherlands in 201-2020 period.

Fig. 7 shows the statistical data relating to the landfill of MW biodegradable in Portugal, between 2006-2010 and the targets set for the year 2006, 2013 and 2020. In accordance with the Landfill Directive (1999/31/EC) the targets are related to the amount of waste produced in 1995, in which Portugal produced approximately 2250000 tons. Contrary to what was expected, since 2006 the amount of MW biodegradable landfill don't decreased.

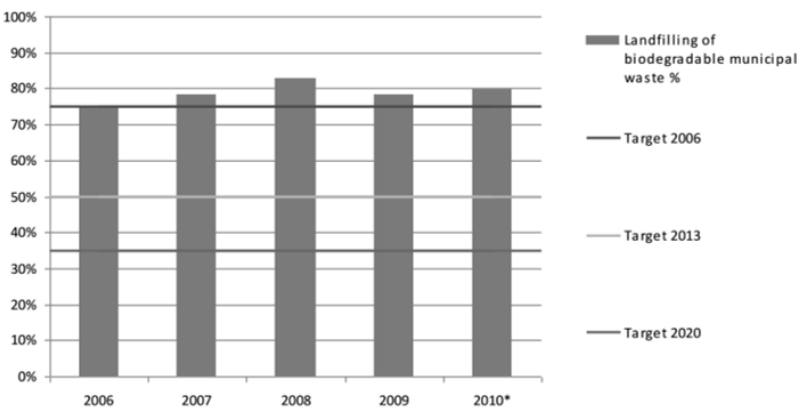

Fig. 7. Landfilling of biodegradable MW in Portugal in the period 2006-2010.

Fig. 8 shows the development of deposition MW biodegradable in landfill on the period 2006-2010 and the targets set for the year 2013, 2016 and 2020, according to the Landfill Directive (1999/31/EC). Due to the recent accession of Croatia to the EU, the year when was established the goals to be achieved was in 1997 with 756,000 tons of MW. Wherefore, this country has to reach $75 \%$ by $2013,50 \%$ by 2016 and $35 \%$ by 2020 . So, Croatia is still far from able to meet the objectives of the Landfill Directive and so need it to take measures emerging in order to combat this problem. A problem not only for the environment, such as for public health.

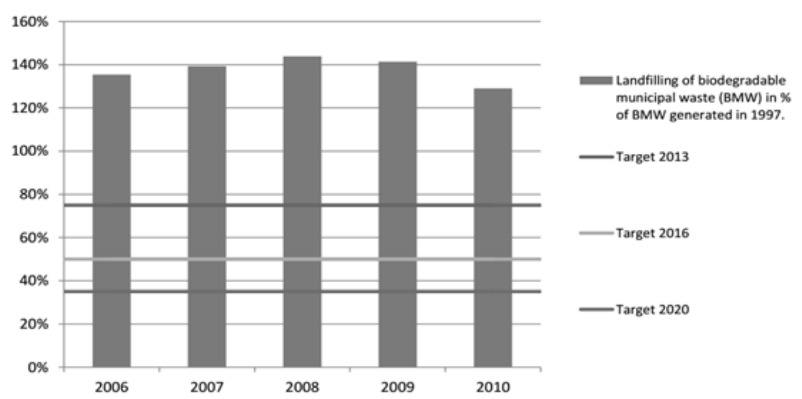

Fig. 8. Landfilling of biodegradable MW in Croatia in the period 2006-2010.

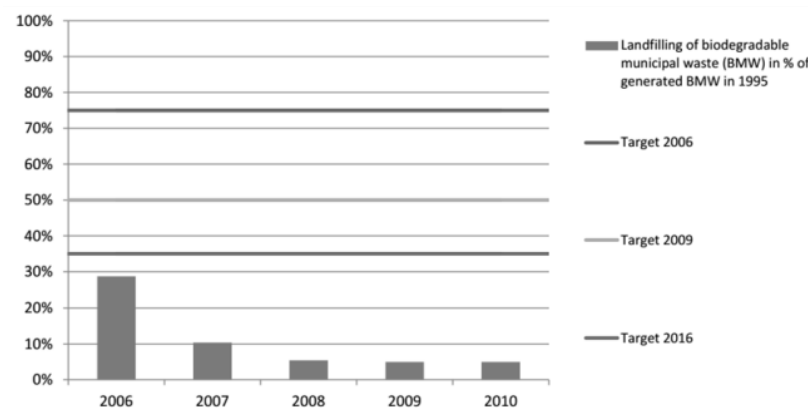

Fig. 9. Landfilling of biodegradable MW in the Netherlands in the period 2006-2010.

Fig. 9 refers to the evolution of the landfilling of biodegradable MW in the Netherlands, 2006-2010 and targets for 2006, 2009 and 2016. In 1995 the Dutch government issued a decree waste, which introduced a ban on landfilling of 35 categories of waste, including biodegradable waste. Exceptionally, is only allowed the deposition of MW 
in Netherlands, where it is obtained a declaration from the environmental authority to indicate that at that time in the Netherlands there is no other treatment option, not to be a landfill. Thus, the amount of MW landfill has decreased over the years, thus fulfilling the objectives set by the directive before the years 2006, 2009 and 2016.

Table I indicates on average the amount of MW produced per person and the type of treatment used to treat the waste in the European Union, in particular in Croatia, the Netherlands, and Portugal in the year 2013. By comparing the production of MW in these three countries with the EU average, it appears that the Netherlands is above the European average, with $526 \mathrm{~kg}$ per person, while the average is $481 \mathrm{~kg}$ per person. Conversely, Croatia is the country that least produces MW per inhabitant, with $404 \mathrm{Kg}$ and then Portugal with $440 \mathrm{~kg}$ per person.

In relation to the recovery of the waste that they are being treated, it is observed that Holland is also in the front line for valuing $50 \%$ of $\mathrm{MW}$, contrary to Croatia in that only $16 \%$ of the residues are valued. In the case of Portugal are recovered
$26 \%$ of MW, in spite of the recovery rate to be higher that of Croatia, Portugal continues to fall short of achieving the targets set, compared with other EU countries.

In a comparative analysis of 2013 values compared to the values mentioned at the beginning of this study (2010), it demonstrates an evolution elapsed in the three year period 2010-2013, considering the MW valued (recycled and composted) $7 \%$ in Portugal, $12 \%$ in Croatia. With regard to the third country under analysis, the rate of recovery hasn't changed, keeping the $50 \%$ and showing a good behavior. [12]

According to the Eurostat data, the deposition of MW landfill is still the most widely used treatment in the majority of countries in the EU, being the most harmful to the environment and to Public Health. [12] Croatia belongs to the group of EU countries with a higher rate of deposition of RU's landfill (85\%), inversely the Netherlands that belongs to the countries with the lowest percentage $(1 \%)$. Once again Portugal is the intermediate level of these two countries, in which the rate of deposition of MW landfill is $50 \%$.

TABLE I: QUANTIFICATION OF PRODUCED MW AND TREATMENTS USED BY EACH COUNTRY, IN 2013

\begin{tabular}{|c|c|c|c|c|c|c|}
\hline & \multicolumn{6}{|c|}{ Municipal Waste 2013} \\
\hline & \multirow{2}{*}{$\begin{array}{l}\text { Generated } \\
\text { (Kg per } \\
\text { person) }\end{array}$} & \multirow{2}{*}{$\begin{array}{l}\text { Treated } \\
\text { (Kg per person) }\end{array}$} & \multicolumn{4}{|c|}{ Municipal Waste Treated \% } \\
\hline & & & Recycled & Composted & Incinerated & Landfilled \\
\hline EU & 481 & 470 & $28 \%$ & $15 \%$ & $25 \%$ & $31 \%$ \\
\hline Croatia & 404 & 396 & $14 \%$ & $2 \%$ & $0 \%$ & $85 \%$ \\
\hline Netherlands & 526 & 526 & $24 \%$ & $26 \%$ & $49 \%$ & $1 \%$ \\
\hline Portugal & 440 & 440 & $13 \%$ & $13 \%$ & $24 \%$ & $50 \%$ \\
\hline
\end{tabular}

\section{DISCUSSION}

The waste production is intrinsically connected to the growth of society and economics, which allows us to understand that in the developed countries, or in developing, there is a growing trend for its increase.

In fact, analyzing the results was observed that the amount of MW increased from the 1990s, but it will very likely that the production of MW decrease in the coming years, due to various situations, such as the economic crisis that is taking place in several European countries. Observing the Fig. 1, Fig. 2 and Fig. 3, it is clear that substantially from the year of 2008 has already noted a slight decrease in the amount of MW, both in Portugal, as in Croatia and in the Netherlands.

Studies show that there are several factors inducing variability in the production of waste, such as seasonal variations, number of inhabitants, purchasing power of the population and efficiency and the type of equipment for the collection [8].

Whereupon, it is possible that sometimes meet significant drops from one year to the other, thus being related to the various existing factors. An example of how a seasonal variation influences the production of MW, is in the year of 2003 in the Netherlands, in which the summer was hotter and drier than normal.

The production of MW always been a concern for the municipalities, by virtue of its legal powers, both environmentally and in terms of public health and therefore became a priority worry also the management of these. In this way, for any waste management policy has as a first option to recycling, immediately after the reduction and reuse, in the scale of priorities [7].

Contradictorily, that is enveloped by Strategic Plans of each country and by Directive Waste there are several studies that emphasized that the sore point of recycling is to know up to that point is that worth, because in some cases, such as the plastic, it is necessary to make the analysis of life cycle. To perform this analysis, it is estimated the fuel used in the transportation of materials from one side to the other, the energy spent in transformation, the pollution caused by the different solutions and the money invested in each one of them. This type of analysis involves several variables and the results can be easily manipulated to point in one direction or another [3].

In relation to the values obtained regarding to recycling (Fig. 4, Fig. 5 and Fig. 6), it is apparent that the rate of recycling with the passing of years has increased, however, in a few countries such as Portugal and Croatia the recycling is still very far from what is expected by 2020 , according to the Directive 2008/98/EC . In 2010, the Netherlands was among the countries with the highest efficiency in the treatment of waste, giving priority to the recycling and composting of biodegradable MW.

Conversely to the Netherlands, the type of treatment most used not only in Croatia, but also in other countries is the MW landfill. As it is shown in Table I it can be observed that most of the waste produced in Croatia (85\%) has as final destination the landfill, so this country not complied with the established target of $50 \%$ for the year 2013. The deposition of MW landfill causes many environmental problems, such as water/soil/atmosphere pollution and the increase of Greenhouse Gases (GHG). These problems are due to the 
production of leachate, which result from the passage of rain water through the waste, and may penetrate the soil and contaminate the groundwater aquifers, or seep into streams or other watercourses. The decomposition of the "organic waste" frees a component, methane, one of the main greenhouse gases, who contributes to the increase in global temperature. Thus, it was designed to Landfill Policy to which the countries opted to other types of treatments.

In accordance to the Landfill Directive, it's clear that despite in Portugal $50 \%$ of MW have as final destination the sanitary landfill, this has failed to meet with the target set for 2013, that is, 2010 to 2013 Portugal fell by $30 \%$ in landfill of waste. It should be noted that there is a favorable development for Portugal, and is a good direction to meet the goal of $35 \%$ in 2020 .

Netherlands is an example in the countries that opt for another type of treatments - only $1 \%$ of MW are deposited in landfill - opting for the valorization of MW (recycling and composting) and by incineration. The incineration, "burning the garbage", was an alternative to landfill in order to reduce the volume of waste, which would have to go to a landfill and reduce the danger of some of its components. However, incineration also leads to some environmental problems, in particular emissions of dioxins and furans. According to the Environmental Protection Agency of north American and the European Environment Agency, these emissions from incinerators were a serious problem for Europe and for the United States in the early 1990s.

Given the results, it appears that this distinction may be due to the fact that the Netherlands be from the start in the EU, that is, always in accordance with European laws that instill this environmental awareness, while Croatia only joined the EU in mid-2013. It is therefore justifiable that this country is far from achieving the $50 \%$ recycling and $35 \%$ of the landfill in 2020, than other countries that are advanced preferably at the level of strategies to decrease production MW and choose the best treatments. It proves that by then the country had a basic waste management policy.

Portugal is an intermediate level compared to these countries, however, doesn't apply in this case one that is considered popular truth "in the middle is the virtue", since Portugal despite having a history of 29 years European Community, it is necessary to continue implementing strategic measures to achieve the target goals of his current SPMSW, to be achieved by 2020 .

\section{CONCLUSION}

The completion of this study allowed to know how actually three countries belonging to the same community environmental space, and such subject to EU legislation regarding MW production and the treatment method. What is demonstrated by an exhaustive study of numbers came prove conclusive distinct realities and how in this small number of core countries the implementation of these measures has results and different levels.

The above mentioned is evidenced by despite the European directives to be fundamental to good waste management, establishing goals and targets to be achieved in certain years, it is also of utmost importance each country own waste management policy.
Given the scenario described, it is crucial that Portugal and Croatia in the size of your needs define and implement measures to address the state of the nation for this problem.

Arises from an empirical finding that Croatia must elect new environmental strategies such as the adoption of waste separation facilities to enable triage thereof, promoting recycling and thus leave the MW deposition in landfills.

Specifically, based on measures such as: buying MW separation containers, establishment of proper and adequate circuit waste collection trucks, building sorting centers and emphasize awareness campaigns.

Regarding to Portugal, the solutions are through creating greater environmental awareness to each citizen, emerges a clearer legislation and imposing, sanctioning improper behavior, of private or business, following the example of several countries of Europe, in particular Switzerland.

Switzerland is taken as a reference because in it is legal system there is a true accountability through the punishment, in breach of the legislation on the separation of waste, in spite of this country does not belong to the EU is governed by it is own laws and exemplary in the environmental area. It is still importantly rethink on the circuit of trucks of waste that allows the placement of domestic waste on the part of the citizens at the front door of buildings, which is then collected by these trucks. These collection circuits are an incentive for that people not to do waste separation, because they have a service even at the door of their homes. Therefore, it is an essential measure extinguish the circuits of municipal regulations that allow lawfully such acts.

To the third country in question, the Netherlands, it is suggested the maintenance of the measures implemented so far, since managed to achieve the objectives proposed by the EU in advance. Not stagnating, it's time to think beyond, and create new goals that maximize as reference country in the field of waste management.

Like early work is expectant, this investigation was no exception, however, was found some limitations of bibliographic order, this because difficulties emerged in lack of current articles and access in digital format, that to prove the veracity of documents available in the official pages of the European Environment Agency and the European Commission.

In a nutshell, the values showed that there were a positive development in the area of the MW and there was a trend to decline its production, such as the deposition of MW in landfills, unlike the recycling that has being increased. Despite of this positive evolution, it is necessary to get more and better in this area, since there are still problems of environmental to tackle, such as the emission of GHG and objectives to fulfill through the European directives.

\section{REFERENCES}

[1] D. Hoornweg and P. Bhada-Tata. (2012). A global review of solid waste management. World Bank. [Online]. Available: www.worldbank.org/urban

[2] Europeia C. A UE e a Gestão dos Resíduos. (2000). Luxemburgo. [Online]. Available: http://europa.eu.int

[3] R. Garcia, Sobre a Terra. cap.12-Resíduos, Lisboa, Público, 2013.

[4] Portugal, Parlamento Europeu. Diretiva 2008/98/CE de 19 de Novembro de 2008, Jornal Oficial da União Europeia. Artigo 4, 2008.

[5] B. Loannis and A. Reichel, Municipal Waste Management in Portugal, EEA, 2013.

[6] M. L. Cruz, "A caracterização de resíduos sólidos no âmbito da sua gestão integrada,” Minho Univ., 2005. 
[7] Portugal, Ministério do Ambiente, Ordenamento do Território e Energia. Portaria n, 187-A de 17 de Setembro de 2014, PERSU 2020.

[8] K. Birgitte and A. Reichel, "Municipal waste management in Croatia," EEA, 2013.

[9] V. Bourgeais. (2015). Each person in the EU generated $481 \mathrm{~kg}$ of municipal waste in 2013. Eurostat. [Online]. Available: http://ec.europa.eu

[10] L. Milios and A. Reichel, "Municipal waste management in the Netherlands," EEA.

[11] Fagar, Gestão de RU's, Caracterização física dos RU's. 2011, p. 1.

[12] European C. Municipal waste statistics. Eurostat Statistics Explained. (2015). [Online]. $\quad$ p. $\quad 1 . \quad$ Available: http://ec.europa.eu/eurostat/statistics-explained

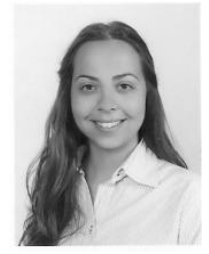

P. Matos is in Environmental Health Technician, the Department of Environmental Health, Coimbra Health School, Polytechnic Institute of Coimbra, Portugal.

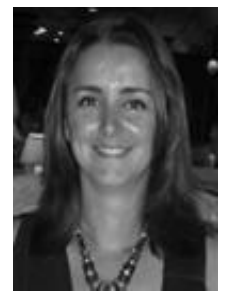

S. Paixão has a degree in environmental health by Coimbra Health School (ESTESC), the master in environmental education from the University of Coimbra, Portugal. She is a $\mathrm{PhD}$ candidate in physical geography in the University of Coimbra and member of the Center for Studies in Geography and Spatial Planning (CEGOT). She holds a certificate of competence to perform the duties of Health and Safety at work technician (certificate of professional competence. She is a certified trainer and she is a accredited trainer of IGC Nebosh from 1996 to 2003, she worked as environmental health technician at Environment Ministery and worked simultaneously in various training courses. From 2003 to 2007, she worked as an environmental health technician at the Health Center of Pombal. she worked as a part time professor in ESTESC from 1999 to 2006. Since 2007 is a full time professor in the Department of Environmental Health at the same school. From June 2011 until may 2015 she was the head of Environmental Health Department. Since 2010, she is one member of the Scientific Technical Council of the same teaching unit. Recently she published scientific papers in national and international journals with referee system in several areas of health and safety and delivered as invited professor various lectures in Portugal and abroad. She coordinated and participated in several national projects in the areas of sustainability, environment, education for health and safety at work.

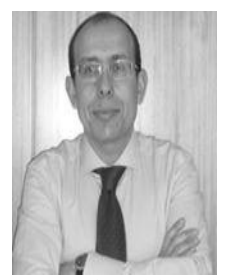

J. P. Figueiredo has a degree in social sciences, the master in sociology and psychology of health and $\mathrm{PhD}$ student in health sciences (specialization in biomedical sciences).

$\mathrm{He}$ is a teacher of statistics, epidemiology, nutritional epidemiology, applied research. He is a supervisor of bachelor and master theses in environmental health, public health, safety and occupational health and biomedical and laboratory sciences.

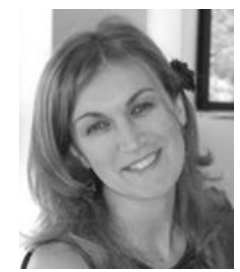

A. Ferreira got the bachelor of hygiene and environmental health (1995) from Coimbra Health School, the master of public health (2004) from Faculty of Medicine, University of Coimbra and the doctoral in health sciences in the Faculty of Medicine, University of Coimbra. She holds postgraduate occupational health from Faculty of Medicine, University of Coimbra and certificate of competence to perform the duties of health and safety advisor and trainer. From 1998 to 2001, she served as an environmental health officer at Condeixa-a-Nova Health Center and the Regional Center for public health. Currently she was called the Department of Public Health and Planning with the following functional areas: planning and health, epidemiological surveillance, environmental and health promotion and protection of health administration. She also collaborated with ESTESC. Currently she is a professor coordinator in the Department of Environmental Health and the president of the scientific committee of the same Department. She is a lecturer of courses: health and environmental education, applied research in environmental health. Since 2009 she has been the vice president of ESTESC. During the several years in ESTESC, she held various positions. She attended and belonged to various organizing committees of courses, seminars, conferences and others. She has authored and co-authored several scientific papers presented at conferences and published in national and international journals on Environmental Health. 